\title{
Demonstration of Earthquake Early Warning Using Total Displacement Waveforms from Real-time GPS Networks
}

\author{
Brendan W. Crowell, Yehuda Bock, and Melinda B. Squibb \\ Scripps Institution of Oceanography, La Jolla, California
}

\section{INTRODUCTION}

Earthquake early warning (EEW) systems have historically been based on traditional seismic instrumentation to provide rapid location of the earthquake source and its magnitude. Seismic-based systems currently exist in Japan (Nakamura 1989; Kanamori 2007), Mexico (Espinosa-Aranda et al. 1995), Taiwan (Wu and Kanamori 2005a, 2005b), Turkey, and Romania (Wenzel et al. 1999; Ionescu et al. 2007), and are under development in California (Allen and Kanamori 2003). Instrumentation includes broadband velocity and strong motion acceleration sensors, which measure dynamic ground motions with great accuracy (e.g., Heaton 1985). Currently, seismic early warning of events requires continuous monitoring of a suite of stations looking for changes in key parameters. Most algorithms use displacement when trying to estimate the potential magnitude of an event from the initial few seconds. The magnitude estimates are made on the ratio of the short-term average displacement to the long-term average and on the apparent frequency of the initial energy. With seismic data, displacement has to be obtained by an integration of the broadband sensors or a double integration of the strong motion sensors. Due to the bandwidth and the dynamic range limits of seismometers, the accuracy of displacements so derived is poor. Seismic instruments are also affected by sensor tilts, long-term drifts, and DC offsets. These problems are not present in displacements measured by continuous GPS (CGPS) instruments. While the seismic measurements provide a powerful constraint on the much noisier GPS measurements, the GPS receiver, unlike the seismometer, measures displacement directly and never clips, making it particularly sensitive to large earthquakes, which are the main focus of EEW.

CGPS instruments can be used to directly measure dynamic displacements ("GPS Seismology"- Nikolaidis et al. 2001; Larson et al. 2003) as well as static (coseismic) displacements ("Earthquake Geodesy"-Bock et al. 1993; Blewitt et al. 1993), from which earthquake magnitude and its source can be inverted. In recent years CGPS networks have proliferated in seismically active regions, e.g., Japan's GEONET (Miyazaki et al. 1998) and UNAVCO's Plate Boundary Observatory
(PBO; http://pboweb.unavco.org/) and its predecessors PGGA, SCIGN, BARD, BARGEN, PANGA, and EBRY in the western U.S. (see http://sopac.ucsd.edu/maps/ for a list of these and other CGPS networks). The primary operating mode for these networks has been daily download of GPS phase and pseudorange data sampled at a 15-30 s sample rate and the production of daily position time series. CGPS networks are now being upgraded to provide even higher-frequency deformation approaching the sampling rates $(1-20 \mathrm{~Hz})$ of modern GPS receivers, with a latency of less than $1 s$ (Genrich and Bock 2006). At these sampling frequencies, CGPS networks become complementary to seismic networks and can be applied to earthquake source modeling (Larson et al. 2003; Hardebeck et al. 2004; Ji et al. 2004; Miyazaki et al. 2004; Bock et al. 2004; Langbein et al. 2005), early warning of natural hazards (Mattia et al. 2004; Dragert et al. 2005; Blewitt et al. 2006; Cervelli et al. 2006; Song 2007), and structural monitoring (bridges, dams, buildings, etc.; Celebi and Sanli 2002; Kogan et al. 2008).

We follow the instantaneous positioning approach of Bock et al. (2000), which was applied to GPS seismology by Nikolaidis et al. (2001). In this method, dual-frequency integer-cycle phase ambiguities and station positions are estimated independently at each epoch for a network of GPS receivers. We refer to the time series of changes in position at a single station, i.e., displacements observed during an earthquake, as a "total displacement waveform" (Figure 1). "Total" refers to the contributions of both dynamic and static displacements. In instantaneous positioning, the displacements are computed relative to one fixed station in the network. Therefore, during an event the displacements are referenced to a station in the network that is not deforming due to the event, or that is being precise point positioned by some other method (e.g., Blewitt et al., 2009). Either way provides "absolute" total displacement waveforms for all deforming stations in the network with respect to a global reference frame.

Langbein and Bock (2004) reported 6-mm horizontal precision at the $99 \%$ confidence level for a few seconds to a few hours of $1-\mathrm{Hz}$ instantaneous positions, with an order of magnitude less precision in the vertical. Genrich and Bock (2006) demonstrated that instantaneous positioning at $10-50 \mathrm{~Hz}$ is 


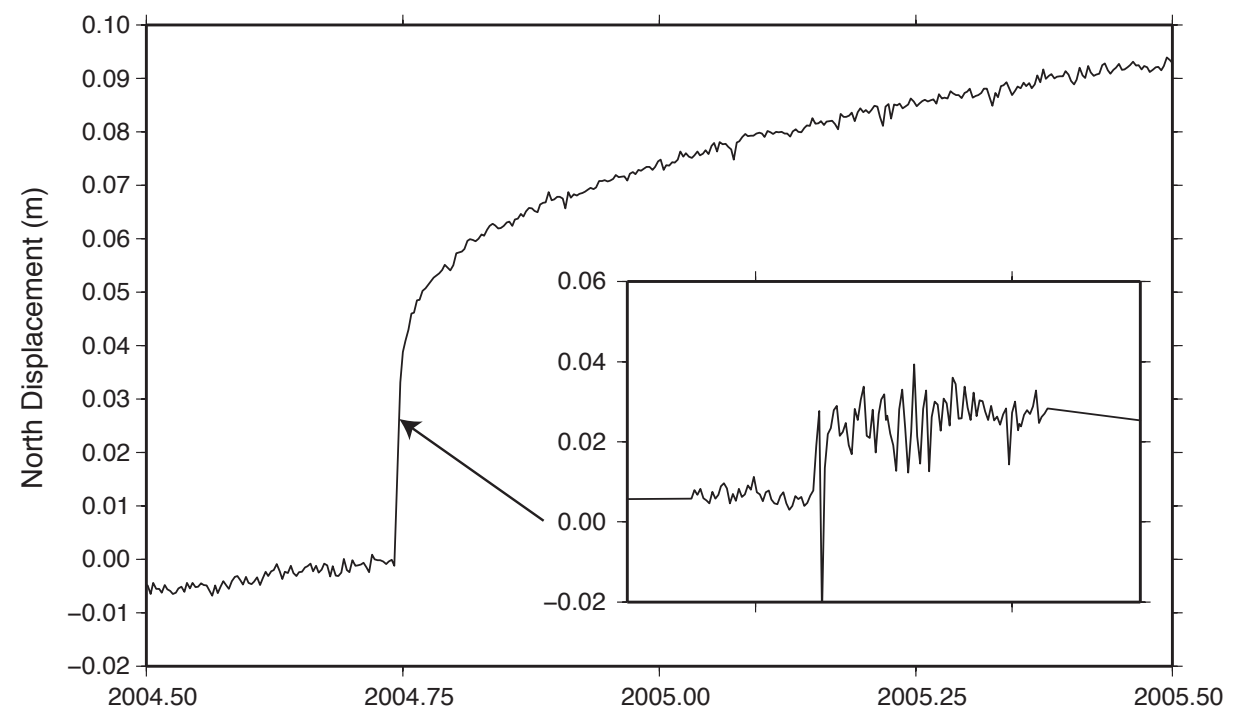

A Figure 1. Time series of 1-Hz total displacement waveforms of station LAND in the period before and after the 2004 Mw6.0 Parkfield earthquake, computed in real time on a PC workstation located at the USGS facility at Carr Hill near Parkfield, using the method of instantaneous positioning. The inset shows dynamic and static displacements during the interval from 07:14 to 07:16 on Sept. 28. The vertical axis is the same in both graphs.

comparable in precision with lower-frequency $(1 \mathrm{~Hz})$ sampling; that is, $\sim 1 \mathrm{~cm}$ horizontal precision and $\sim 5 \mathrm{~cm}$ vertical precision for a single displacement for station spacing up to several tens of kilometers. They concluded that very-high-frequency response is flat ("white noise") above $0.05-0.5 \mathrm{~Hz}(<2-20 \mathrm{~s}$ ), which is a distinct advantage for EEW applications since the receiver sampling rate can be increased without loss of precision.

In this paper, we provide two examples of how a geodetic EEW system can be used within the current limitations of realtime GPS networks. In the first example, we replayed $1-\mathrm{Hz}$ GPS data and computed total displacement waveforms, in a simulated real-time mode, from the $2003 \mathrm{Mw}$ 8.3 Tokachi-Oki thrust earthquake (e.g., Miyazaki et al. 2004) off Hokkaido Island and estimated earthquake hypocenter, magnitude, and source parameters. This earthquake was recorded by the Japan national CGPS network, GEONET, operated by the Geographical Survey Institute (GSI) (Miyazaki et al. 1998). GEONET has 1,156 stations with $20 \mathrm{~km}$ spacing (Figure 2) streaming $1-\mathrm{Hz}$ data to a central facility in Tsukuba. Individual triangular elements were processed for 410 stations in northern Japan, and the two principal components of strain rate were computed every second for each triangular element (Figure 2).

The second example uses the California Real Time Network (CRTN-Genrich and Bock 2006; Aydin et al. 2007; http://sopac.ucsd.edu/projects/realtime/) in southern California (Figure 3) for the ShakeOut scenario in November 2008 (Jones et al. 2008). Since 2002, more than 100 CGPS stations in southern California have been upgraded to a $1-\mathrm{Hz}$ sample rate with a latency of less than $1 \mathrm{~s}$, including stations from the SCIGN and PBO networks. Baselines in CRTN are generally less than $40 \mathrm{~km}$, and in areas of higher seismic activity and faulting the baselines are on the order of $10-20 \mathrm{~km}$. We computed synthetic total displacement waveforms before the
ShakeOut event using the prespecified earthquake parameters and played these through a prototype EEW system.

We finish by giving an example of integrating geodetic and seismic EEW systems from a study done at UCSD's outdoor shake table simulating the 1994 Northridge earthquake. The two data streams can be combined through a multirate Kalman filter that creates a higher-frequency displacement waveform than the GPS waveform with an associated reduction in noise.

\section{PROTOTYPE EARTHQUAKE EARLY WARNING SYSTEM IN SOUTHERN CALIFORNIA}

Our prototype EEW system is outlined in Figure 4. It relies on a dense network of real-time stations with average spacing in the 20-40 km range. Japan's GEONET, the Western Canada Deformation Array (WCDA), the Bay Area Regional Deformation Network (BARD), parts of the Plate Boundary Observatory (PBO), and CRTN are all geodetic quality networks that fulfill these requirements. With CRTN, 1-Hz data are streamed over dedicated microwave and radio links provided by the University of California at San Diego (UCSD)'s HPWREN (High Performance Wireless Research and Education Network; http://hpwren.ucsd.edu) project, with a latency of a fraction of a second. Scripps Institution of Oceanography (SIO) telemetry buffers with short- and long-term storage capabilities are deployed at stations to help minimize data loss. The raw data streams are then processed at the Scripps Orbit and Permanent Array Center (SOPAC; http://sopac.ucsd.edu) using the method of instantaneous positioning (Bock et al. 2000) implemented in the RTD Pro software. On the server side, we combine current epoch CGPS coordinates for the CRTN stations, ultra-rapid SOPAC orbits (http://garner.ucsd.edu/pub/products/), and the NOAATrop model (Gutman 2008) to reduce single epoch displacement uncertainties down to the centimeter level in the hori- 


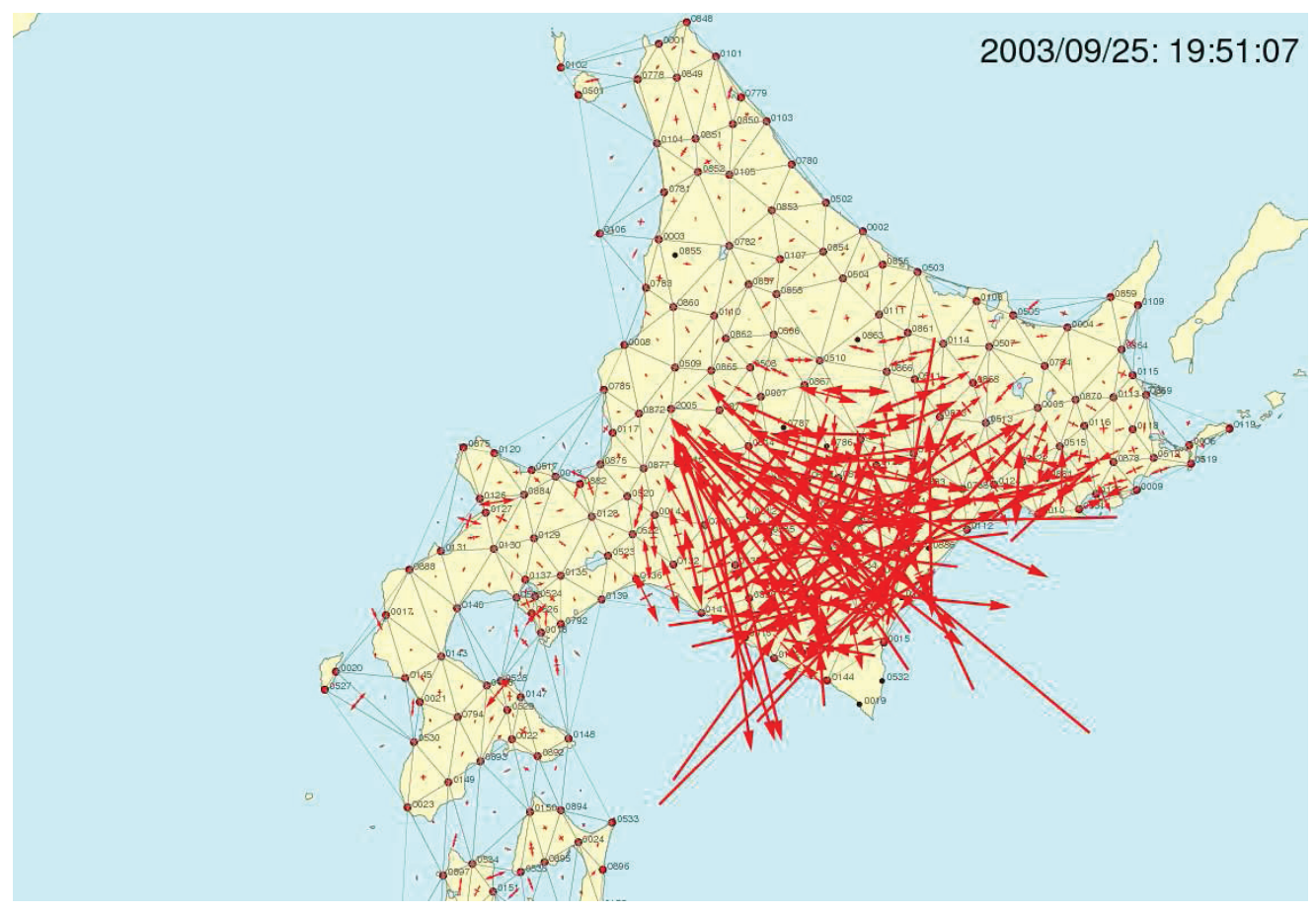

A Figure 2. Delaunay triangulation of GEONET stations on Hokkaido Island and the two principal components of strain in each triangle for a single epoch during the $2003 \mathrm{Mw} 8.3$ Tokachi-0ki thrust earthquake.

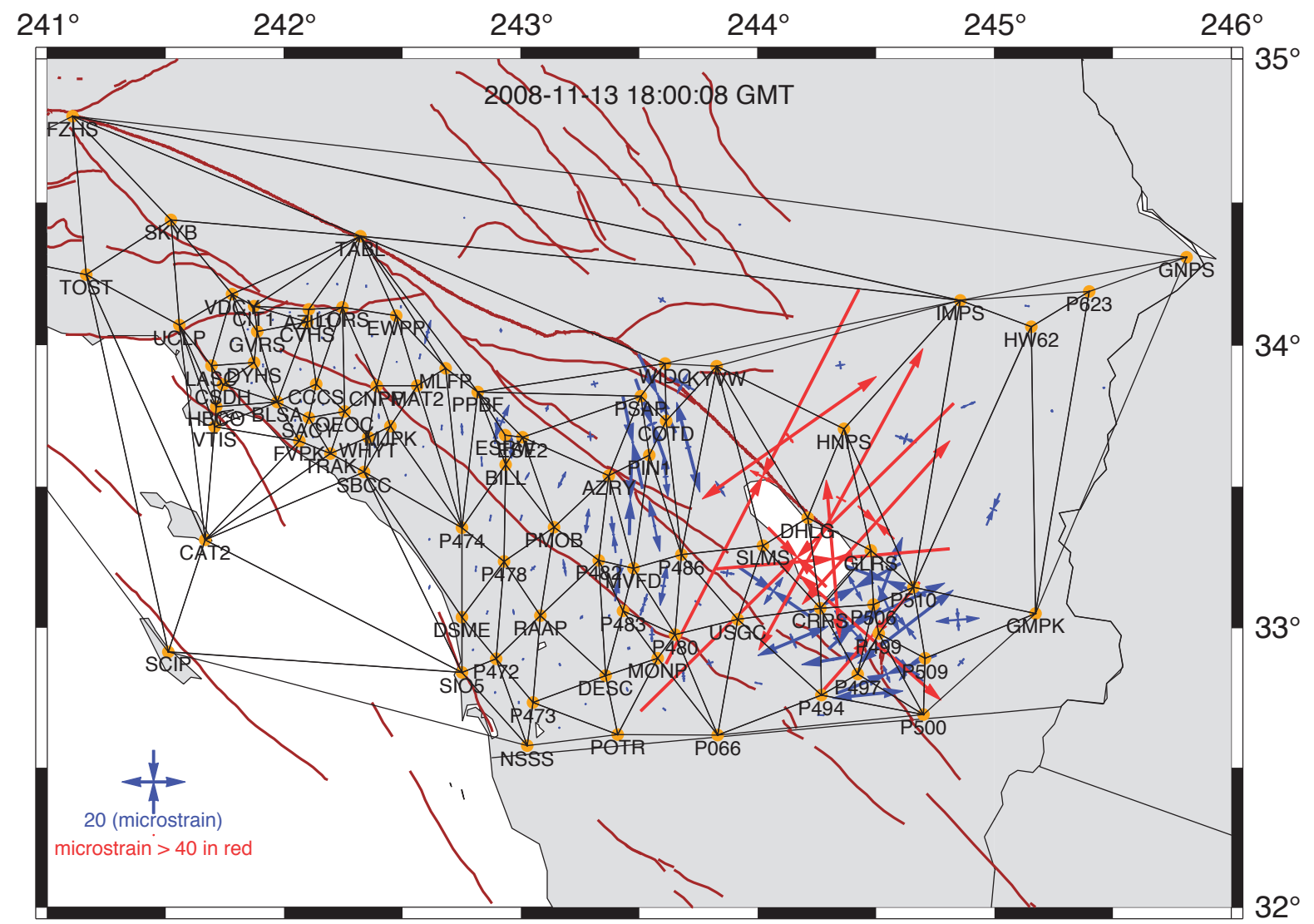

- Figure 3. Delaunay triangulation of the two principal components of strain rate at 18:00:08 GMT during the 2008 Shake0ut simulated earthquake, using total displacement waveforms computed at each CRTN station. The earthquake initiates at 18:00:00 GMT near station DHLG and stops near station TABL. The red lines represent the triangles in which the strain rate has exceeded the threshold of 40 $\mu$ strain and the blue lines are under the threshold. For the strain rate in real time for CRTN, see http://ingress.ucsd.edu/strainTest. 


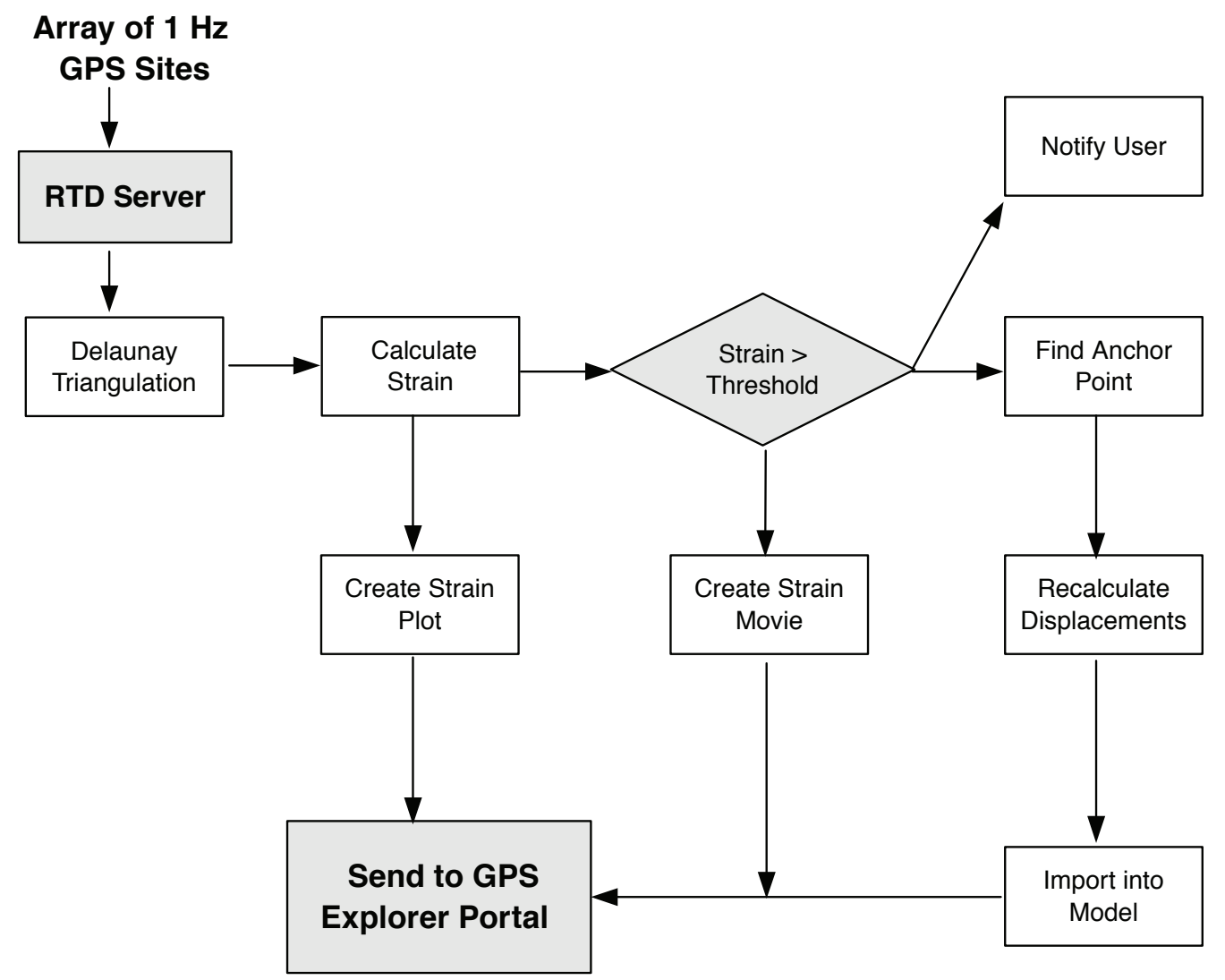

$\Delta$ Figure 4. Flowchart for prototype geodetic EEW system developed at SOPAC. Data from CRTN are processed for instantaneous positions, and then the network is triangulated and the principal components of strain are computed. If strain exceeds a prespecified threshold, e-mail alerts are sent out, a strain movie is created, and absolute positions are computed through a network adjustment. From here, earthquake modeling will provide earthquake source parameters and issue alerts to key personnel. All information is archived in the GPS Explorer data portal (http://geoapp.ucsd.edu).

zontal and several centimeters in the vertical. To reduce computation time, the data analysis is performed on a set of (currently) eight subnetworks of 10-15 stations each, with one-station overlap between subnetworks. Each subnetwork produces a time series of displacement waveforms, relative to an arbitrary master station. The subnetworks are then stitched together on-the-fly to produce a single network whose displacement waveforms (still relative to an arbitrary master station) are accessible through a single IP port in a binary format called RYO.

Anomalous strain detection is determined by first creating a Delaunay triangulation grid over all the CRTN stations that recorded a position during the last second. From here, we follow the methods of Feigl et al. (1990) to compute the two principal components of strain rate in each triangle from relative changes in the lengths of the sides of the triangles, with one station tightly constrained. A map of the strain in the network is then created and is updated every second at http://ingress. ucsd.edu/strainTest (Figure 3). Once strain reaches a prespecified threshold, an e-mail alert is disseminated to key personnel. The e-mail contains the time in GMT, each station in the triangle, and the value of the maximum principal component of strain. Also, a strain movie of the event is archived to be replayed later. Anomalous strain detection depends on the distance of the network from the earthquake hypocenter. As we show in examples from the ShakeOut and 2003 Tokachi-Oki earthquakes, strain detection can be in the first few seconds or up to 20 seconds or more after the initiation of the earthquake.

Under normal circumstances when there is no ground motion, the relative positions can essentially be taken as absolute (say, with respect to the network's centroid). When ground motion is present, every part of the network is being deformed in a different way, so we need to perform a network adjustment every epoch in order to obtain the absolute total displacement waveforms with respect to the International Terrestrial Reference Frame (ITRF; Altamimi et al. 2007). When an event occurs and there is anomalous strain in three or more triangles, we begin the network adjustment process. We do this by finding the station farthest away from the maximum strain triangle and fixing the coordinates of that station, either from known CRTN coordinates in ITRF (if the station is not deforming due to the event), or with respect to coordinates of one (or more) stations in the network derived using a precise real-time point positioning service (we are currently evaluating NASA's Global Differential GPS (GDGPS) System; http:// www.gdgps.net/). The basic network adjustment solution to transform from relative to absolute displacement waveforms (when errors are not considered) is simply $A x=b$, where $A$ is an $m$ by $n+1$ design matrix, $x$ is a vector of positions of length 


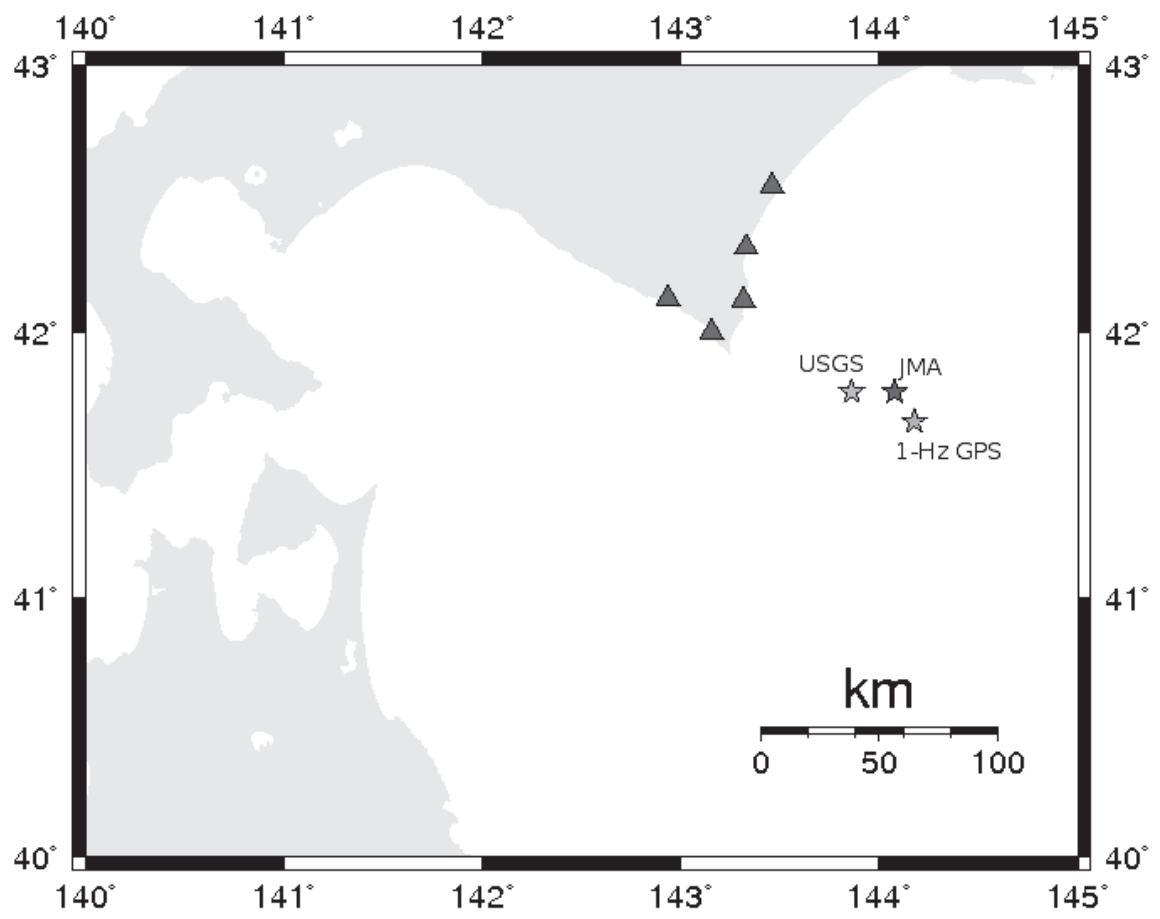

A Figure 5. Hypocenter determination for the 2003 Mw 8.3 Tokachi-Oki earthquake off the coast of Hokkaido Island, Japan. The triangles represent the first five stations to have more than $0.1 \mathrm{~m}$ of total displacement during the earthquake sequence, and thus used in determining the hypocenter of the earthquake. The stars represent the USGS and JMA epicenters determined using seismic data and our estimated hypocenter using 1-Hz GPS data.

$m$, and $b$ is a vector of baselines of length $n+1$. Since the design matrix is most likely sparse and the problem is overdetermined, we use a QR decomposition that utilizes Householder reflections and solve the problem by least squares. The absolute total displacement waveforms so derived are the most important aspect in EEW since all of the modeling relies directly on them.

It should be noted that the entire process described in this section can be performed on-the-fly with a latency of 1-2 s, using IP communications and standard computer workstations located at a central processing facility.

\section{HYPOCENTER ESTIMATION}

The next step is to determine the earthquake hypocenter, which is performed when displacements of four or more GPS stations exceed preset criteria of total displacement. The system currently uses $0.1 \mathrm{~m}$, which is 5-10 times greater than the precision of a single displacement estimate (Genrich and Bock 2006). The first station to exceed the displacement limit is set to $t=0$. Prior to hypocenter determination, a preset grid in ITRF coordinates is created for the area that encompasses the entire geographic area down to $100 \mathrm{~km}$ depth with $5-\mathrm{km}$ grid spacing. Once four stations have exceeded the displacement limit, we find the distance from each GPS station to every grid point in the local grid, which is defined as $d$. Then we minimize the $L_{1}$ norm of the predicted time difference of arrival between the four GPS stations, which is the distance difference divided by the wave speed, $v$, minus the actual time difference of arrivals, $t$, between the four GPS stations such that

$$
r_{\min }=\min \left[\sum_{i=1}^{3} \sum_{j=2}^{4}\left|\frac{d_{j}-d_{i}}{v}-\left(t_{j}-t_{i}\right)\right|\right]
$$

The value of $r_{\min }$ is associated with a distance from the earthquake source to the first GPS station, which is then divided by $v$ to obtain the time offset, $t_{o}$, of earthquake rupture. We then use the offset time computed from the predicted time difference to minimize the $L_{2}$ norm of the actual arrival time minus the predicted arrival time from each local grid point:

$$
s_{\min }=\min \left[\sqrt{\sum_{i=1}^{4}\left|t_{i}+t_{o}-\frac{d_{i}}{v}\right|^{2}}\right] .
$$

The value of $s_{\text {min }}$ is then associated with an ITRF position in the grid, which is our hypocenter estimate.

The hypocenter estimate for the 2003 Tokachi-Oki earthquake, for which we replayed 1-Hz GEONET data and computed (absolute) total displacement waveforms in a simulated real-time mode, is shown in Figure 5. The epicenter estimate from the GPS measurements is roughly $23 \mathrm{~km}$ and $43 \mathrm{~km}$ away from the Japan Meteorological Agency (JMA) and U.S. Geological Survey (USGS) epicenter estimates, respectively. The depth of the earthquake was computed to be $5.9 \mathrm{~km}$, which is much shallower than the $42 \mathrm{~km}$ and $27 \mathrm{~km}$ estimates from 
the JMA and USGS, respectively. There are a few caveats with this method using 1-Hz GPS measurements.

First, the low sampling rate effectively rounds up the arrival time at each GPS station, which can easily cause errors in the hypocenter determination of the order of the wave speed. Second, the displacement threshold of $0.1 \mathrm{~m}$ is a major cause for concern. While this seems to be a good determinant from visual inspection of records that a large earthquake has started to affect the GPS station, this may not be representative of the actual arrival time of the earthquake, further making the estimate error prone. Wu and Kanamori (2005b) suggest that if the initial peak ground displacement (PGD) from the first three seconds of a $P$-wave arrival is greater than $0.005 \mathrm{~m}$, then the event will be damaging at the site and that the initial PGD is approximately related linearly with the final PGD. Scaling relationships from Wu et al. (2006) show that an initial PGD of $0.1 \mathrm{~m}$ at $10 \mathrm{~km}$ from the hypocenter indicates an earthquake magnitude of 5.9; at $100 \mathrm{~km}$ the magnitude is 7.9 .

The third major source of error is the selection of grid spacing of $5 \mathrm{~km}$. A smaller grid would provide more accuracy, but this increases the computation time. For example, when running this grid search algorithm in MATLAB for the 2003 Tokachi-Oki earthquake, a grid spacing of $10 \mathrm{~km}$ takes roughly 0.5 seconds, but a grid spacing of $5 \mathrm{~km}$ takes about three seconds. However, one could perform a very rough grid search and then a finer grid search of a much smaller area to reduce computation time.

\section{MODELING EARTHOUAKE MAGNITUDE THROUGH SCALING RELATIONSHIPS}

Little is known about how total PGD scales as a function of hypocentral distance, or the evolution of PGD through the entire earthquake cycle, because high-rate GPS measurements have not existed in a considerable spatial density until recent years. Only a handful of events have taken place in areas with good high-rate GPS coverage. Also of interest is the scaling of the total coseismic displacement compared to the PGD during an earthquake to determine relationships between them as well as how coseismic displacement scales with PGD during the first few seconds. In order to rapidly determine the magnitude of impending earthquakes, we need to look at how other earthquakes behave from the first few seconds of seismic motion all the way to the end of the earthquake. Determining the final rupture of an earthquake from the first few seconds is very difficult, because no one knows if the earthquake will rupture part of the fault or the entire fault. Probabilistic approaches have been used to infer whether an earthquake rupture will continue or stop based upon the seismic record to that point (e.g., Cua and Heaton 2007).

According to the JMA, the origin time of the 2003 Tokachi-Oki earthquake is 19:50:07 UTC (19:50:20 GPS time) at an epicenter of $\left(41.780^{\circ} \mathrm{N}, 144.079^{\circ} \mathrm{E}\right)$ and a depth of $42 \mathrm{~km}$ (Yamanaka and Kikuchi 2003). For the first 20 seconds of the earthquake, no GPS stations reported anomalous displacement. At 19:50:28 UTC, a station located $84.89 \mathrm{~km}$ from the hypocenter showed $152 \mathrm{~mm}$ of total displacement (Figure 6). No other stations at this time had displacement over 100 $\mathrm{mm}$. In the next second, a station $90.6 \mathrm{~km}$ from the hypocenter showed $114 \mathrm{~mm}$ of displacement, and the station $84.89 \mathrm{~km}$ away had a displacement of $213 \mathrm{~mm}$. The next station to exhibit over $100 \mathrm{~mm}$ of total displacement was located $95.7 \mathrm{~km}$ away at 19:50:31 UTC. It took another three seconds to obtain two more stations with anomalous displacement, which were 108 and $110.5 \mathrm{~km}$ away from the hypocenter. At 19:50:34 UTC, a determination of earthquake hypocenter can be made. At this point, a rapid determination of earthquake magnitude is necessary within a few seconds. For the Tokachi-Oki earthquake, seismic wave propagation takes between 70 and 100 seconds to travel across Hokkaido Island.

Direct measurements of PGD at $1 \mathrm{~Hz}$ exist for the 2003 Tokachi-Oki earthquake. From Figure 7, we can draw parallels between PGD and coseismic displacement at each site. The difference between the two can be approximated by a linear trend on a log-log plot. The implication from this is very simple. The difference between the PGD and coseismic displacement decreases the farther a station is located from the earthquake hypocenter. This is due to the fact that the attenuation of dynamic displacement is greater as it decays proportional to $r^{-1}$, where $r$ is the radial distance from the source, whereas the decay in coseismic displacement is proportional to $r^{-2}$ (Aki and Richards 1980). Since final magnitude is directly related to the coseismic displacement, being able to relate it to the initial or final PGD will prove very valuable in magnitude determination for EEW. Figure 6 shows that PGD is reached in less than 15 seconds after the earthquake arrives at a station, and the first stations affected reach half their final PGD by the time a hypocenter is computed. Further investigations into the time dependence of PGD will hopefully be useful in bridging the gap between PGD and coseismic displacement.

When we compare coseismic displacement of the TokachiOki earthquake to the 1999 Hector Mine and 2004 Parkfield earthquakes, we see that coseismic displacement as a function of hypocentral distance is linear on a log-log plot for all three events, even exhibiting roughly the same slope (Figure 8). High-rate GPS measurements did not exist during the Hector Mine earthquake and only for a small number of stations during the Parkfield earthquake, so we cannot draw parallels between PGD and coseismic displacement for these two earthquakes. However, through scaling relationships and some other assumptions, we hope to draw meaningful conclusions about these smaller earthquakes.

\section{EARTHOUAKE SOURCE MODEL ESTIMATION}

We have also been experimenting with rapid determination of earthquake source models (Figure 9) from the coseismic displacements of the 2003 Tokachi-Oki earthquake. Prior to running the model, we defined the coordinates of the blocks and fault nodes (23 along-strike and nine down-dip components) to be included in the inversion. We created a file of 90 slip vector azimuths by searching the Global CMT catalog for earth- 

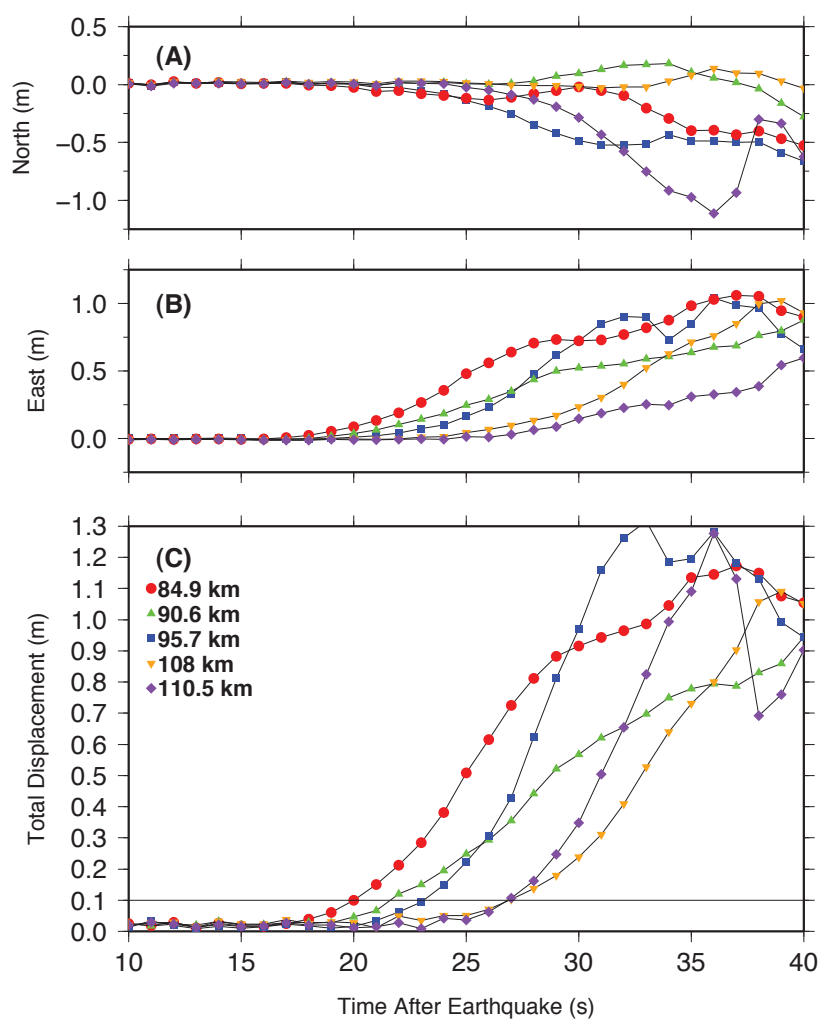

A Figure 6. The north (A), east (B), and total (C) displacement $\left(\left(\text { East }^{2}+\text { North }^{2}+U p^{2}\right)^{1 / 2}\right)$ for the first five stations to exhibit more than $10 \mathrm{~cm}$ of total displacement and used for the hypocenter determination.

quakes greater than $M w 6.0$ in the vicinity of Hokkaido Island. The inversion is performed using DEF-NODE, a program that uses the models of Okada $(1985,1992)$ and a simulated annealing approach to estimate model parameters (McCaffrey 1995). We have reduced the time to generate a full model inversion to about 15 minutes. When performing the inversion, the only variable parameter is the hypocenter, which we find through our grid search method. For the Tokachi-Oki earthquake, we obtain a moment magnitude of 8.09 , maximum slip of $7 \mathrm{~m}$ at depth of $15 \mathrm{~km}$, dip between $20^{\circ}$ and $25^{\circ}$, and strike $\sim 250^{\circ}$. This is roughly in agreement with earthquake source parameters estimated by other studies (Yamanaka and Kikuchi 2003; Yagi 2004; Miura et al. 2004).

Although the calculation needs to be sped up to be part of a viable EEW, it is extremely useful for decision makers and earthquake researchers to have a source model estimate even in its current form, and it may be useful for tsunami warning.

\section{SHAKEOUT EXPERIMENT: EEW SYSTEM IN ACTION}

On 13 November 2008 at 10:00 a.m., a simulated $M w 7.8$ earthquake along the southern San Andreas fault (SAF) took place in order to test the emergency preparedness of southern California for a large earthquake as part of the "Great Southern California ShakeOut" (Jones et al. 2008). This event

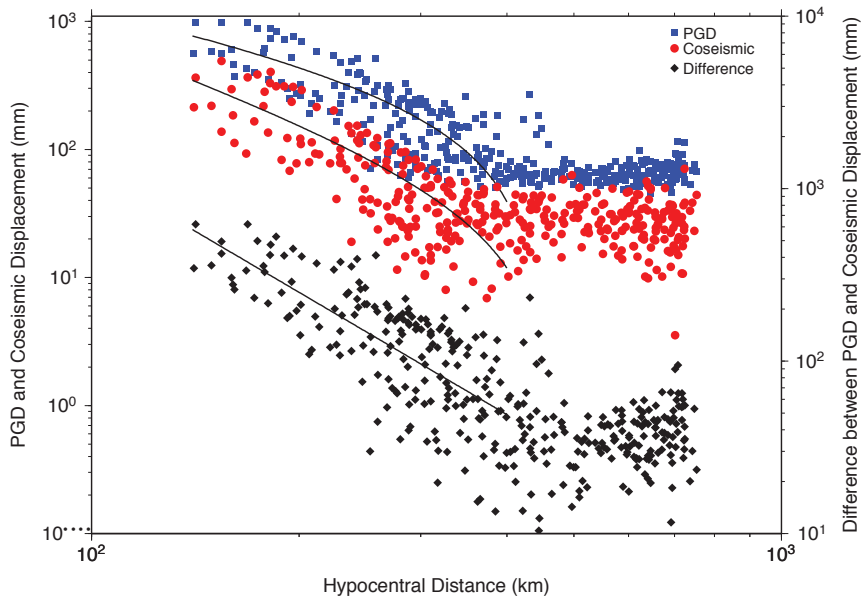

A Figure 7. Peak ground displacement, coseismic displacement and the difference between the two as a function of hypocentral distance for the 2003 Mw 8.3 Tokachi-Oki earthquake. For the PGD and coseismic displacements, the best fit curves of $r^{-1}$ and $r^{-2}$ are shown up to $400 \mathrm{~km}$ away from the hypocenter. For the difference between the two displacements, the best fit curve shown is linear in log-log space up to a hypocentral distance of $400 \mathrm{~km}$.

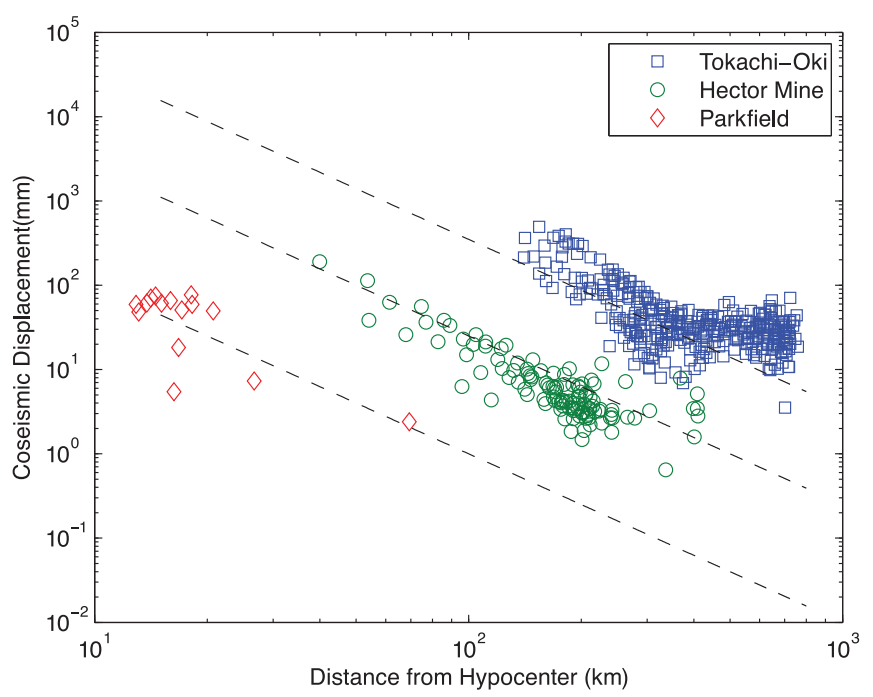

- Figure 8. Coseismic displacement as a function of distance from hypocenter for the $2003 \mathrm{Mw} 8.3$ Tokachi-Oki earthquake, the 1999 Mw 7.1 Hector Mine earthquake, and the 2004 Mw 6.0 Parkfield earthquake. The dashed lines are lines of slope $r^{-2}$, representing the decay in coseismic displacement with hypocentral distance.

is an ideal candidate for EEW since the propagation of seismic waves would take 70-90 seconds to reach the Los Angeles basin from the initial rupture point. In response to the 2008 ShakeOut earthquake scenario, we created synthetic total displacement waveforms for each of the GPS stations in CRTN. The location of stations (Figure 3) is ideal for an event along 


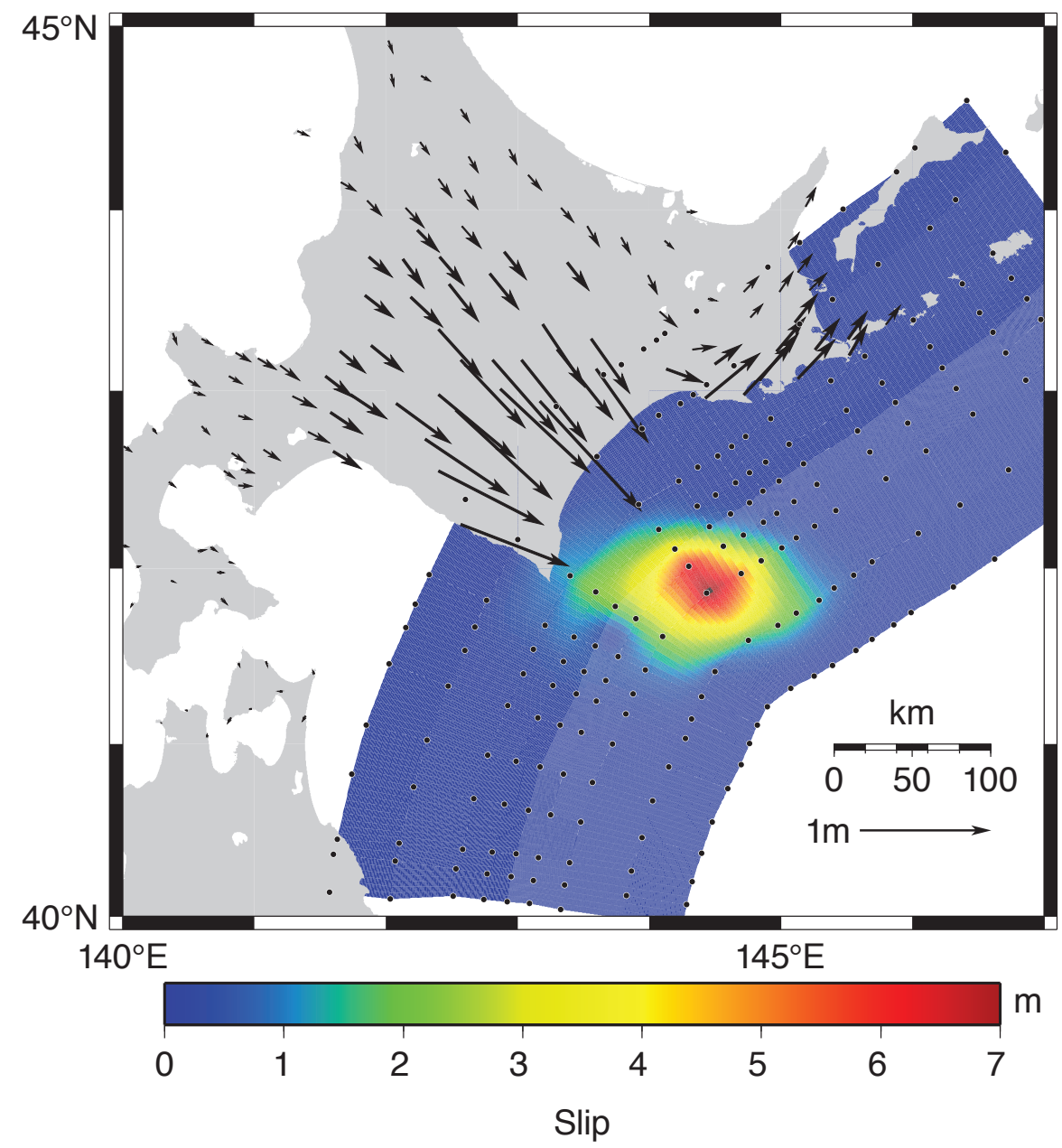

$\Delta$ Figure 9. Coseismic inversion of the first 10 minutes of data from the 2003 Tokachi-0ki earthquake. The GPS vectors are the coseismic displacements observed from the first 10 minutes of data and used in the inversion. The black dots are fault nodes that are determined before the inversion.

the southern SAF because they straddle both sides of the fault as well as many of the smaller auxiliary faults such as the San Jacinto, Imperial, Elsinore, and Superstition Hills faults. We created the synthetic waveforms by creating 30 earthquake sources evenly spaced along the SAF from Bombay Beach to Lake Hughes and associated each source with an amplitude, start time, and starting depth based upon the parameters used by Jones et al. (2008). The amplitudes are directly related to the amount of slip along each segment of the fault. Slip initiates around Bombay Beach and has a very high slip value of $6.54 \mathrm{~m}$ for a roughly $70-\mathrm{km}$-long segment of fault until the San Gorgonio Pass, in which slip drops to $3.12 \mathrm{~m}$ for about $100 \mathrm{~km}$. When the rupture exits the Cajon Pass, the slip increases once again to $4.20 \mathrm{~m}$ to the ending point around Lake Hughes, a roughly $120-\mathrm{km}$ segment. We then used the rupture speed of the earthquake to compute the source time for each source. The rupture speeds were $0.95 \mathrm{~V}_{s}, 0.75 \mathrm{~V}_{s}$, and $0.85 \mathrm{~V}_{\mathrm{s}}$ for the first, second, and third fault segments respectively. The source depths were defined to be $11 \mathrm{~km}, 16.8 \mathrm{~km}$, and $13 \mathrm{~km}$ for the first, second, and third fault segments, respectively.
To compute the synthetic displacement waveforms, we use normal modes on a string and sum up the first 200 modes. We included an azimuthal term to include the direction of first motion and determine the horizontal and vertical (NEU) components and an attenuation term to ensure the waveform dies off at large distances away from the fault. In this formulation, the earth structure is assumed to be homogeneous. Although this approximation may not be very accurate since there are great compositional differences between the San Bernardino Mountains and the Los Angeles basin, it provides a good first approximation of the expected displacements. In addition, this method does give a rough estimate of how much shaking will take place, which is all we need to prove that our warning system method is effective. The final step in creating our synthetic displacement waveforms is to add the coseismic offset term, which is computed through a screw dislocation model for strike slip faults (e.g., Scholz 2002). The coseismic term is added into the synthetic waveform once the waveform displays at least $0.1 \mathrm{~m}$ of total displacement.

On the date of the ShakeOut event, we input the synthetic displacement waveforms into our warning system (Figure 4) 
as if the synthetics were the actual ITRF2005 positions coming out of the RTD server. We simulated a telemetry outage at station USGC near the epicenter since an earthquake of this magnitude could potentially take out communications links for one or many stations. The warning system detected anomalous strain for the first $70 \mathrm{~s}$ after the earthquake initiation and disseminated e-mail alerts to key personnel. In a real event, all steps up to this point could be done with a latency of 1-2 s. Automatic modeling of the earthquake was not done in real time simply because this has yet to be integrated into the system. Within minutes of the event, a new event Web site was created on the GPS Explorer portal (http://geoapp.ucsd.edu), a joint project of SOPAC and Jet Propulsion Laboratory (JPL) to provide user-friendly GPS data products (Webb et al. 2007). On the ShakeOut GPS Explorer page, the following products were provided: total displacement waveforms, hourly RINEX files, coseismic deformation models, strain simulations, and the cached strain movie. These data products can then be used by emergency first responders and researchers to determine where the most damage is located, so as to assist those in need as well as perform rapid-response GPS surveys to look at postseismic deformation signals and aftershocks.

\section{JOINT GEODETIC/SEISMIC WARNING SYSTEM}

GPS and seismic instruments can be mutually beneficial in implementing an EEW system because weaknesses in one system are offset by strengths in the other. The greatest strength that GPS provides is total displacement waveforms, which can be used directly to estimate earthquake source parameters. In order for seismic instruments to provide displacement measurements, integration is required, which amplifies low-frequency noise in the computed displacement waveforms. Also, the integration is oblivious to any jumps such as coseismic displacement, which the GPS antenna will directly measure. The main weaknesses in current GPS measurements are the lower sampling rates and the larger high-frequency noise contribution. Seismic instruments are able to sample at very high rates and perform very well in the high-frequency range.

One possible integration scheme would include a multirate Kalman filter, as described by Smyth and Wu (2006) and applied by Kogan et al. (2008) to bridge monitoring, on collocated GPS and seismic instruments (Bock et al. 2008). The multirate Kalman filter is a recursive filter that utilizes the displacement measurements from GPS as a constraint in integrating the seismic velocities or accelerations. This effectively creates a higher rate displacement waveform with smaller errors than both the direct GPS measurements and the integrated seismic instruments. This concept was shown to be effective during a test at the George E. Brown Jr. Network for Earthquake Engineering Simulation (NEES) large highperformance outdoor shake table at USCD. The building was instrumented with geodetic-quality Navcom NCT-200D GPS receivers sampling at $50 \mathrm{~Hz}$ and DA52 DC accelerometers sampling at $250 \mathrm{~Hz}$ and subjected to accelerations of low to high intensity recorded by accelerometers during the 1971 San
Fernando and 1994 Northridge earthquakes. Instantaneous $50-\mathrm{Hz}$ displacement waveforms were recorded in real time for five GPS receivers mounted on the building with respect to a sixth static reference receiver located just off the shake table's platen. A seventh receiver was situated on the platen, whose motion was recorded at a $1,024-\mathrm{Hz}$ rate by the shake table's MTS 469DU digital controller. The purpose of this receiver is to determine the accuracy of the displacement waveforms with respect to the "truth" provided by the MTS controller. The receiver located on the platen had a root mean square (RMS) difference of $3.7 \mathrm{~mm}$ with respect to the MTS controller during a replay of the 1994 Northridge earthquake. The doubly integrated accelerometer data had an RMS difference of 10.2 $\mathrm{mm}$ with respect to the MTS controller and had a considerable low-frequency noise amplification as well as underestimation in many of the peaks. With the multirate Kalman filter, the resulting $250-\mathrm{Hz}$ displacement waveforms had an RMS difference of $3.3 \mathrm{~mm}$. More details on this experiment are provided in Bock et al. (2009).

Another possible scheme would be to use seismic instruments for initial detection, since they are much more sensitive to small ground motions, and then use the GPS displacements for determination of earthquake source parameters. This method has advantages over the multirate Kalman filter technique since it does not require collocated GPS and seismic instruments, which are currently rare in California.

\section{CONCLUSIONS}

We are currently developing an EEW system based upon realtime GPS measurements in southern California, with plans to expand to a statewide network. We already publish the realtime strain map for our network, disseminate e-mail alerts, and create total displacement waveforms at $1 \mathrm{~Hz}$. Hypocentral determination has yet to be integrated and different earthquake modeling techniques are still being investigated for speed, reliability, and accuracy. PGD scaling relationships could prove very beneficial, but more data is needed from large earthquakes with a high spatial density of 1-Hz-or-greater GPS stations. Collaborations from the seismic and geodetic communities could prove highly beneficial to both parties, and integration of the two systems could be accomplished in the near future. $<$

\section{ACKNOWLEDGMENTS}

We acknowledge the Southern California Integrated GPS Network and its sponsors, the W. M. Keck Foundation, NASA, NSF, USGS, and SCEC; the Plate Boundary Observatory operated by UNAVCO for EarthScope (http://www.earthscope.org) and supported by NSF grant EAR-0323309; Jose Restrepo and Marios Panagiotou (UCSD); and Basara Miyahara and Atsushi Yamagiwa (GSI, Japan) for data used in this study. Use of the Geodetics, Inc. RTD software was provided by UCSD. We thank Rob Clayton and Sharon Kedar for comments on seismic early warning systems, and Peng Fang and Paul Jamason at SOPAC for their assistance. Reviews by 
Richard Allen and an anonymous reviewer are appreciated. This study was funded by NASA grants (SENH) NAG5-13269 and (AIST) NNX09AI67G.

\section{REFERENCES}

Aki, K., and P. G. Richards (1980). Quantitative Seismology: Theory and Methods. New York: W. H. Freeman.

Allen, R. M., and H. Kanamori (2003). The potential for earthquake early warning in Southern California. Science 300, 786-789.

Altamimi, Z., X. Collilieux, J. Legrand, B. Garayt, and C. Boucher (2007). ITRF2005: A new release of the International Terrestrial Reference Frame based on time series of station positions and Earth Orientation Parameters. Journal of Geophysical Research 112 , B09401; doi:10.1029/2007JB004949.

Aydin, G., Z. Qi, M. E. Pierce, G. C. Fox, and Y. Bock (2007). Architecture, performance, and scalability of a real-time Global Positioning System data grid. Physics of the Earth and Planetary Interiors 163, 347-359; doi:10.1016/j.pepi.2007.04.012.

Blewitt, G., W. C. Hammond, C. Kreemer, H.-P. Plag, S. Stein, and E. Okal (2009). GPS for real-time earthquake source determination and tsunami warning systems. Journal of Geodesy 83, 335-343; doi:10.1007/s00190-008-0262-5.

Blewitt, G., M. Heflin, K. Hurst, D. Jefferson, F. Webb, and J. Zumberge (1993). Absolute far-field displacements from the 28 June 1992 Landers earthquake sequence. Nature 361, 340- 342.

Blewitt, G., C. Kreemer, W. C. Hammond, and H. P. Plag (2006). Rapid determination of earthquake magnitude using GPS for tsunami warning systems. Geophysical Research Letters 33, L11309; doi:10.1029/2006GL026145.

Bock, Y., B. Crowell, F. Webb, S. Kedar, R. Clayton, and B. Miyahara (2008). Fusion of high-rate GPS and seismic data: Applications to early warning systems for mitigation of geological hazards. Eos, Transactions, American Geophysical Union 89 (53), Fall meeting supplement, Abstract G43B-01.

Bock, Y., P. Agnew, J. Fang, B. Genrich, T. Herring, K. Hudnut, et al. (1993). Detection of crustal deformation from the Landers earthquake sequence using continuous geodetic measurements, Nature 361, 337-340.

Bock, Y., R. Nikolaidis, P.J. de Jonge, and M. Bevis (2000). Instantaneous geodetic positioning at medium distances with the global positioning system. Journal of Geophysical Research 105, 28,233-28,253.

Bock, Y., L. Prawirodirdjo, and T. I. Melbourne (2004). Detection of arbitrarily large dynamic ground motions with a dense high-rate GPS network. Geophysical Research Letters 31; doi:10.1029/2003GL019150.

Bock, Y., F. Yang, M. Panagiotou, and J. Restrepo (2009). Accuracy of absolute displacement waveforms using GPS and accelerometer data from outdoor shake table experiments: Implications for geological early warning systems.

Celebi, M., and A. Sanli (2002). GPS in pioneering dynamic monitoring of long period structures. Earthquake Spectra 18, 47-61.

Cervelli, P. F., T. Fournier, J. Freymueller, and J. A. Power (2006). Ground deformation associated with the precursory unrest and early phases of the January 2006 eruption of Augustine Volcano, Alaska. Geophysical Research Letters 33; doi:10.1029/2006GL027219.

Cua, G., and T. Heaton (2007). The Virtual Seismologist (VS) method: A Bayesian approach to earthquake early warning. In Earthquake Early Warning Systems, ed. P. Gasparini, G. Manfredi, and J. Zschau, 97-130. Berlin and Heidelberg: Springer (ISBN-13 9783-540-72240-3).

Dragert, H., M. Schmidt, K. Wang, and Y. Bock (2005). A Canadian pilot project for a GPS-augmented tsunami warning system. Eos, Transactions, American Geophysical Union 86 (52), Fall meeting supplement, Abstract G13A-05.
Espinosa-Aranda, J., A. Jimenez, G. Ibarrola, F. Alcantar, A. Aguilar, M. Inostroza, and S. Maldonado (1995). Mexico City seismic alert system. Seismological Research Letters 66 (6), 42-53.

Feigl, K. L., R. W. King, and T. H. Jordan (1990). Geodetic measurement of tectonic deformation in the Santa Maria fold and thrust belt, California. Journal of Geophysical Research 95 (B3), 2,679-2,699.

Genrich, J. F., and Y. Bock (2006). Instantaneous geodetic positioning with $10-50 \mathrm{~Hz}$ GPS measurements: Noise characteristics and implications for monitoring networks. Journal of Geophysical Research 111, B03403; doi:10.1029/2005JB003617.

Gutman, S. I. (2008). Troposphere signal delay corrections, http://gpsmet.noaa.gov/jsp/downloads/Trop_Delay_Corrections.pdf.

Hardebeck, J. L., J. Boatwright, D. Dreger, R. Goel, V. Graizer, K. Hudnut, et al. (2004). Preliminary report of the 22 December 2003, M 6.5 San Simeon, California earthquake. Seismological Research Letters 75 (2), 155-172.

Heaton, T. (1985). A model for a seismic computerized alert network. Science 228 (4,702), 987-990; doi:10.1126/science.228.4702.987.

Ionescu, C., M. Böse, F. Wenzel, A. Marmureanu, A. Grigore, and G. Marmureanu (2007). An early warning system for deep Vrancea (Romania) earthquakes. In Earthquake Early Warning Systems, ed. P. Gasparini, G. Manfredi, and J. Zschau, 343-349. Berlin and Heidelberg: Springer (ISBN-13 978-3-540-72240-3).

Ji, C., K. M. Larson, Y. Tan, K. W. Hudnut, and K. Choi (2004). Slip history of the 2003 San Simeon earthquake constrained by combining 1-Hz GPS, strong motion, and teleseismic data. Geophysical Research Letters 31, L17608 ; doi:10.1029/2004GL020448.

Jones, L. M., J. R. Bernknopf, D. Cox, J. Goltz, K. Hudnut, D. Mileti, S. Perry, et al. (2008). The ShakeOut Scenario. USGS Open File Report 2008-1150 and California Geological Survey Preliminary Report 25; http://pubs.usgs.gov/of/2008/1150/.

Kanamori, H. (2007). Real-time earthquake damage mitigation measures. In Earthquake Early Warning Systems, ed. P. Gasparini, G. Manfredi, and J. Zschau, 1-8. Berlin and Heidelberg: Springer (ISBN-13 978-3-540-72240-3).

Kogan, M. G., W.-Y. Kim, Y. Bock, and A. W. Smyth (2008). Load response on the Verrazano Narrows Bridge during the NYC Marathon revealed by GPS and accelerometers. Seismological Research Letters 79 (1), 12-19.

Langbein, J., and Y. Bock (2004). High-rate real-time GPS network at Parkfield: Utility for detecting fault slip and seismic displacements. Geophysical Research Letters 31; doi:10.1029/2003GL019408.

Langbein, J., R. Borcherdt, D. Dreger, J. Fletcher, J. Hardebeck, M. Hellweg, C. Ji, et al. (2005). Preliminary report on the 28 September 2004 M 6.0 Parkfield, California earthquake. Seismological Research Letters 76 (1), 10-21.

Larson, K., P. Bodin, and J. Gomberg (2003). Using 1-Hz GPS data to measure deformations caused by the Denali fault earthquake. Science 300, 1,421-1,424.

Mattia, M., M. Rossi, F. Guglielmino, M. Aloisi, and Y. Bock (2004). The shallow plumbing system of Stromboli Island as imaged from $1 \mathrm{~Hz}$ instantaneous GPS positions. Geophysical Research Letters 32; doi:10.1029/2004GL021281.

McCaffrey, R. (1995). DEF-NODE User's Guide. Troy, NY: Rensselaer Polytechnic Institute.

Miyazaki, S., H. Tsuji, Y. Hatanaka, and T. Tada (1998). The nationwide GPS array as an Earth observation system. Bulletin of the Geographical Survey Institute 44, 11-22.

Miyazaki S., K. M. Larson, K. Chai, K. Hikina, K. Koketsu, P. Bodin, J. Haase, G. Emore, A. Yamagiwa, et al. (2004). Modeling the rupture process of the 2003 September 25 Tokachi-Oki (Hokkaido) earthquake using 1-Hz GPS data. Geophysical Research Letters 31, L21603; doi:10.1029/2004GL021457.

Miura, S., Y. Suwa, A. Hasegawa, and T. Nishimura (2004). The 2003 M 8.0 Tokachi-Oki earthquake-how much has the great event paid back slip debts? Geophysical Research Letters 31, L05613; doi:10.1029/2003GL019021. 
Nakamura, Y. (1989). Earthquake alarm system for Japan Railways. Japanese Railway Engineering 28 (4), 3-7.

Nikolaidis, R., Y. Bock, P. J. de Jonge, P. Shearer, D. C. Agnew, and M. Van Domselaar (2001). Seismic wave observations with the Global Positioning System. Journal of Geophysical Research 106, 21,89721,916.

Okada, Y. (1985). Surface deformation to shear and tensile faults in a half-space. Bulletin of the Seismological Society of America 75, $1,135-1,154$.

Okada, Y. (1992). Internal deformation due to shear and tensile faults in a half-space. Bulletin of the Seismological Society of America 82, $1,018-1,040$.

Scholz, C. M. (2002). The Mechanics of Earthquakes and Faulting. 2nd ed. Cambridge and New York: Cambridge Univ. Press, 471 pps.

Smyth, A., and M. Wu (2006). Multi-rate Kalman filtering for the data fusion of displacement and acceleration response measurements in dynamic system monitoring. Mechanical Systems and Signal Processing 6,174; doi:10.1016/j.ymssp.2006.03.005.

Song, Y. T. (2007). Detecting tsunami genesis and scales directly from coastal GPS stations. Geophysical Research Letters 34; doi:10.1029/2007GL03168.

Webb, F., Y. Bock, S. Kedar, D. Dong, P. Jamason, R. Chang, L. Prawirodirdjo, I. Macleod, G. Wadsworth, et al. (2007). GPS data exploration for seismologists and geodesists. Eos, Transactions, American Geophysical Union 88 (52), Fall meeting supplement, Abstract G13B-1231.

Wenzel, F., M. Oncescu, M. Baur, and F. Fiedrich (1999). An early warning system for Bucharest. Seismological Research Letters 70 (2), $161-169$.
Wu, Y.-M., and H. Kanamori (2005a). Experiment on an onsite early warning method for the Taiwan early warning system. Bulletin of the Seismological Society of America 95, 347-353.

Wu, Y.-M., and H. Kanamori (2005b). Rapid assessment of damage potential of earthquakes in Taiwan from the beginning of $P$ waves. Bulletin of the Seismological Society of America 95, 1,181-1,185.

Wu, Y.-M., H.-Y. Yen, L. Zhao, B.-S. Huang, and W.-T. Liang (2006). Magnitude determination using initial $P$ waves: A single station approach. Geophysical Research Letters 33, L05306; doi:10.1029/2005GL025395.

Yagi, Y. (2004). Source rupture process of the 2003 Tokachi-Oki earthquake determined by joint inversion of teleseismic body wave and strong ground motion data. Earth Planets and Space 56, 311-316

Yamanaka, Y., and M. Kikuchi (2003). Source process of the recurrent Tokachi-Oki earthquake on September 26, 2003, inferred from teleseismic body waves. Earth Planets and Space 55, e21-e24.

Cecil H. and Ida M. Green Institute of Geophysics and Planetary Physics Scripps Institution of Oceanography University of California, San Diego 9500 Gilman Drive La Jolla, California 92093-0225, U.S.A. bwcrowel@ucsd.edu

(B. W. C.) 